\title{
Dissociation of anosognosia and phantom movement during the Wada test
}

\author{
L H Lu, A M Barrett, J E Cibula, R L Gilmore, E B Fennell, K M Heilman
}

Department of Clinical and Health

Psychology, College of Health Professions,

University of Florida, Gainesville, FL, USA

L H Lu

E B Fennell

Department of Neurology, College of Medicine, University of Florida, Box 100236, Gainesville, FL

32610-0236, USA

R L Gilmore

E B Fennell

K M Heilman

Neurology Service, Malcom Randall VA

Medical Center, Gainesville, FL, USA

K M Heilman

Division of Neurology, Department of

Medicine,

Pennsylvania State

University School of

Medicine, Hershey,

PA, USA

A M Barrett

Department of

Neurology, University of Kentucky,

Lexington, KY, USA

J E Cibula

Correspondence to:

Dr K M Heilman

heilman@medicine.ufl.edu

Received 22 October 1999 and in revised form

27 July 2000

Accepted 14 August 2000

\begin{abstract}
Objective-Patients who misperceive that they are moving their paralysed arm (phantom movements) may not recognise its weakness. Therefore, the relation between phantom limb movements and anosognosia for hemiplegia during selective right hemispheric anaesthesia (the Wada test) was examined.

Methods-Nine patients with intractable epilepsy underwent the Wada test. During the right hemispheric injection, after the onset of hemiparesis, anosognosia was assessed by asking patients if they were weak. The patient's vision was limited such that they could not see the position of their limbs. Phantom movements were tested for by asking patients to attempt to lift their left upper limb, and to demonstrate their left limb's position by placing their right limb in the same position as their left. Proprioception was tested by lifting the patient's paretic upper limb and having patients demonstrate this position by lifting their right limb to the same position.

Results-Three patients experienced left phantom limb movements, and five were anosognosic for their hemiplegia. However, phantom movement occurred in only one patient with anosognosia. The other two patients with phantom movement were without anosognosia. The patient with phantom movement and anosognosia had impaired proprioception. The two patients with phantom movement but without anosognosia had intact proprioception.

Conclusions-Phantom movement in the presence of a proprioceptive deficit could contribute to anosognosia. However, anosognosia and phantom movement are dissociable; therefore phantom movement cannot alone account for anosognosia. Because phantom movement occurred with and without proprioceptive deficits, proprioceptive loss is not a prerequisite for phantom movement.

(F Neurol Neurosurg Psychiatry 2000;69:820-823)
\end{abstract}

Keywords: anosognosia; phantom movement; Wada test

Anosognosia, or unawareness of deficit, can occur in patients with hemiplegia, amnesia, or aphasia. ${ }^{1-4}$ Although associated with right cortical insult, anosognosia is not directly attributable to any other neuropsychological deficit..$^{5-13}$ In this paper, we will use the term anosognosia to refer to unawareness or denial of a hemiparesis, as first described by Babinski. ${ }^{14}$

In a previous study in our laboratory, ${ }^{13}$ patients with anosognosia did not realise that their left hand was weak even after attempting to move it while it was in view. As phantom sensations of movement may occur in patients with cerebral dysfunction, ${ }^{15-21}$ we wished to learn whether patients with anosognosia deny their weakness because they misperceive that they can move their paralysed forelimb. Heilman $^{22}$ suggested that when the prefrontal/ premotor cortex sends discharges to the motor cortex to execute a movement, it also sends corollary discharges, or an efferent copy, to the somatosensory cortex or association areas that contain representations of the body and serve as a comparator. ${ }^{23-25}$ Normally, sensory representations activated from this efferent copy are compared with peripherally generated impulses generated by the limb executing the movement. A hypothetical comparator determines if intended and executed movements match. If they do not match, the comparator sends this information to the premotor cortex to correct discrepancies. Phantom movements may occur when the comparator malfunctions and corollary discharges accompanying intended movements are interpreted as movement feedback. This misidentification may occur especially with proprioceptive impairment, as efferent copies of intended movements may be the only input the comparator receives.

When patients perceive movement in a paralysed limb, they may conclude that they are not weak. If anosognosia can be explained by perception of phantom movements, there should be a direct relation between the occurrence of phantom movement and anosognosia. This relation should be especially strong when proprioception of the plegic limb is impaired.

\section{Methods}

SUBJECTS

Nine patients with intractable epilepsy being evaluated for surgery were involved in the study. As part of their evaluation, they underwent selective hemispheric anaesthesia 
Table 1 Demographic and neurological data for patients, organised so as to demonstrate the dissociation between phantom movements and anosognosia

\begin{tabular}{lllllllll}
\hline Patient No & Sex/age & $\begin{array}{l}\text { Education } \\
(y)\end{array}$ & FSIQ & $\begin{array}{l}\text { Seizure } \\
\text { focus/pathology }\end{array}$ & $\begin{array}{l}\text { Side of } \\
\text { Focus }\end{array}$ & $\begin{array}{l}\text { Phantom limb } \\
\text { movement }\end{array}$ & Anosognosia & Proprioception \\
\hline 1 & $\mathrm{~F} / 31$ & 14 & 97 & T/hip & $\mathrm{R}$ & + & - & + \\
3 & $\mathrm{M} / 20$ & 12 & 67 & F and T/none & $\mathrm{L}$ & + & - & + \\
7 & $\mathrm{~F} / 53$ & 11 & 79 & T/hip & $\mathrm{R}$ & + & + & - \\
2 & $\mathrm{M} / 38$ & 12 & 95 & T/none & $\mathrm{R}$ & $-\star$ & + & + \\
5 & $\mathrm{~F} / 33$ & 13 & 85 & Unknown & Unknown & $-\star$ & + & + \\
6 & $\mathrm{M} / 34$ & 12 & 80 & F/none & $\mathrm{L}$ & - & + & + \\
9 & $\mathrm{M} / 38$ & 12 & 94 & T/hip & $\mathrm{R}$ & $-\star$ & + & + \\
$4 \dagger$ & $\mathrm{M} / 34$ & 12 & 72 & T/hem & $\mathrm{R}$ & - & - & + \\
$8 \ddagger$ & $\mathrm{F} / 48$ & 13 & 91 & T/unknown & $\mathrm{L}$ & - & - & + \\
Mean & 37 & 12 & 84 & & & & & + \\
$\mathrm{SD}$ & $(10)$ & $(1)$ & $(11)$ & & & & & +
\end{tabular}

Patients are numbered in the order that they came to our clinic. All patients were right handed and had left hemispheric dominance for language as determined by the Wada test unless indicated otherwise. FSIQ=Full scale IQ estimated from WAIS-R; T=temporal; hip=hippocampal sclerosis; $\mathrm{T} / \mathrm{hem}=$ temporal hemosiderosis; $\mathrm{F}=$ frontal; $\mathrm{L}=$ left; $\mathrm{R}=$ right; $+=$ present. $-=$ absent. ${ }^{\star}$ These patients were able to move their limb minimally when asked to do so during the phantom movement trial; †left handed subject; the Wada test indicated bilateral dominance for language.

(Wada test). We tested patients during the right carotid injection because anosognosia occurs more often after right hemispheric anaesthesia. ${ }^{26-28}$ Seizure foci were determined by surface EEG, MRI, and neuropsychological data. If no seizure focus was identified using these methods, subdural EEG electrode monitoring was performed. Neurological and demographic data for each patient are shown in the table. This project was approved by the institutional review board, and all patients gave informed consent.

PROCEDURE

We trained patients immediately preceding the Wada procedure. All patients mastered the tasks and showed intact proprioception during training. Standard clinical procedure at our institution is to inject the right hemisphere first. Minimal methohexital (Brevital, Jones Medical Industry, St Louis, MO, USA) dosage, inducing hemiparesis but not sedation, totalling 3-5 $\mathrm{mg}$, was determined by the electroencephalographer monitoring the procedure. Hemiparesis was measured using a dynamometer before and after injection, and after testing. Clinically, language and memory were assessed by asking patients to repeat, follow commands, name objects, and recall objects presented. The anaesthetic effect of methohexital lasted about 3 minutes. After clinical assessment, patients received for the study another, equal, dose of methohexital.

During research testing, patients wore goggles limiting their vision so that they could not see their arms. After methohexital injection, when the patient's left forelimb became plegic, patients were asked, "Are you weak?" This question was phrased generally to capture any awareness of weakness. If patients responded negatively, they were considered to be anosognosic. Four test trials followed: (1) We assessed phantom movements by asking patients to raise their paralysed left forelimb, then asked if their left limb was raised. Once they gave an affirmative response, they were instructed to "make your right limb do what your left limb is doing." Proprioception was considered intact when patients correctly demonstrated their left limb position using their right limb. (2) Proprioception was assessed by the examiner raising the patients' left forelimb when they were not attempting to move their left forelimb, then asking patients to demonstrate their left limb's position by placing their right limb in the same position. Phantom movement was defined as having occurred when patients raise their right limb (to demonstrate left limb position) while their left limb lay paralysed on their chest. (3) To examine task comprehension, we lifted the patients' right limb, returned it to its original position, then asked patients to demonstrate its previous position. (4) In a second "control" trial, while the left forelimb rested on the patients' chest, we asked patients to demonstrate their left limb position with their right limb. Accurate response was demonstrated when patients left their right limb resting on their chest. By requiring patients to demonstrate with their non-paretic limb the position of their left limb, we eliminated the need for the patient to respond verbally and the possibility that patients' verbal responses may reflect deduction of movement from intention rather than actual movement.

The order of the trials was counterbalanced. Two raters independently rated anosognosia, phantom movement, and proprioception. A third rater's independent rating was used for one patient due to incongruent ratings from the two raters.

Each patient was tested for about 10 minutes (orient patient, obtain baseline dynamometer reading, methohexital injection, obtain postinjection dynamometer reading, query about weakness, execute the four test trials one time, obtain post-testing dynamometer reading, wait for EEG to return to baseline, reorient patients).

\section{Results}

The average dynamometer readings were 37, 4, and $27 \mathrm{~kg}$ at baseline, after injection, and after testing. All patients responded accurately on both control tasks, which indicated that they did not have problems understanding or performing the tasks during hemispheric anaesthesia. Results are presented in the table.

Of the nine patients in this study, five had anosognosia and three demonstrated phantom movements. Phantom movements occurred in two non-anosognosic patients and in one patient with anosognosia. Of the three patients who demonstrated phantom movements, two 
had intact proprioception and one had impaired proprioception. The patient with phantom movements and impaired proprioception was also anosognosic. Thus one patient fitted our predicted pattern of co-occurrence of phantom movements and anosognosia with deficient proprioception. However, anosognosia occurred with and without phantom movement, and both anosognosia and phantom movements occurred in the presence of intact proprioception.

Because dynamometer readings after testing were not as low as after injection, it was possible that results were affected by recovery from the anaesthetic effect. We examined the order of trials and found that phantom movement was tested last in patients 2, 5, and 9. They made some movements when asked to move their weak limb, suggesting that the anaesthetic effect had weakened by this time. All three were anosognosic. It is possible that testing for phantom movement earlier would have resulted in co-occurrence of phantom movements and anosognosia in these patients. However, this does not alter our finding that phantom movements and anosognosia occurred as dissociable phenomena in two patients.

\section{Discussion}

We found that phantom left limb movement and anosognosia for hemiplegia can be induced during right hemispheric anaesthesia. However, we did not find a direct relation between them. Anosognosia cannot be an inevitable result of phantom movement alone because phantom movement occurred with and without anosognosia. However, if phantom movement were a necessary but insufficient factor for anosognosia, we would still expect every instance of anosognosia to be accompanied by phantom movement, but we did not find this relation in all patients. Therefore, the presence of phantom movement may not be critical for anosognosia and may only contribute to anosognosia when no feedback is available.

In the absence of visual feedback, we expected that phantom movement would be associated with impaired proprioception, but two patients with intact proprioception demonstrated phantom movement and three patients had impaired proprioception but did not experience phantom movements. These findings suggested that proprioceptive impairment was neither necessary nor sufficient for the experience of phantom movements. We also examined the relation between proprioception and anosognosia and found a similar dissociation.

We reanalysed our results to eliminate bias introduced by atypical brain organisation and the side of seizure focus. Reanalysing our data excluding patients with bilateral language mediation and other than right sided foci still maintained the dissociation between anosognosia and phantom movement (patients 1, 2, and 9). We considered that the risk that drug induced hemiparesis might have partially worn off in the course of the study. Our results would have been confounded if we had not found evidence of phantom movements or anosognosia late in the course of the study. Instead, despite wearing off effects, patients demonstrated both phantom movements and anosognosia as dissociable phenomena.

We have demonstrated that patients may perceive phantom movements in the paretic limb during right hemispheric anaesthesia. This occurred in three out of nine patients. If this phenomenon occurs at a similar rate in patients with brain injury, phantom movement may be more common than previously thought.

We thank Jeff Anderson for being our "blind" rater and David Beversdorf for his assistance in data collection. This research was supported by the National Institutes of Health grant RO1NS30639, the State of Florida Department of Elder Affairs and the Medical Research Service of the Department of Veterans Affairs.

1 Bisiach E, Geminiani G. Anosognosia related to hemiplegia and hemianopia. In: Prigatano GP, Schacter DL, eds. Awareness of deficit after brain injury: clinical and theoretical issues. New York: Oxford University Press, 1991:17-39.

2 Schacter DL. Unawareness of deficit and unawareness of knowledge in patients with memory disorders. In: Prigatano GP, Schacter DL, eds. Awareness of deficit after brain injury: clinical and theoretical issues. New York: Oxford University Press, 1991:127-51.

3 Rubens AB, Garrett MF. Anosognosia of linguistic deficits in patients with neurological deficits. In: Prigatano GP, Schacter DL, eds. Awareness of deficit after brain injury: clinical and theoretical issues. New York: Oxford University Press, 1991:40-52.

4 Kaplan RF, Cohen RA, Jones-Woodward L, et al. Awareness of deficit after the sodium amobarbital test. F Int Neuropsychol Soc 1997;3:8

5 Starkstein SE, Fedoroff JP, Price TR, et al. Neuropsychoogical deficits in patients with anosognosia. Neuropsychiatry Neuropsychol Behav Neurol 1993;6:43-8.

6 Feinberg TE. Anosognosia and its relationship to confabulation. Presented at American Academy of Neurology, 48th Annual Meeting. San Francisco: AAN, 1996.

7 McGlynn SM, Schacter DL. Unawareness of deficits in neuropsychological syndromes. F Clin Exp Neuropsychol 1989;11:143-205.

8 Levine DN. Unawareness of visual and sensorimotor defects: a hypothesis. Brain Cogn 1990;13:233-81.

9 Levine DN, Calvanio R, Rinn WE. The pathogenesis of anosognosia for hemiplegia. Neurology 1991;41:1770-81.

10 Heilman KM. Anosognosia: possible neuropsychological Heilman KM. Anosognosia: possible neuropsychological
mechanisms. In: Prigatano GP, Schacter DL, eds. Awareness of deficit after brain injury: clinical and theoretical issues. New York: Oxford University Press, 1991:53-62.

11 Adair JC, Na DL, Schwartz RL, et al. Anosognosia for hemiplegia: test of the personal neglect hypothesis. Neurology 1995;45:2195-9.

12 Lu LH, Barrett AM, Schwartz RL, et al. Anosognosia and confabulation during the Wada test. Neurology 1997;49: 1316-22.

13 Adair JC, Schwartz RL, Na DL, et al. Anosognosia: examining the disconnection hypothesis. I Neurol Neurosurg Psychiatry 1997;63:798-800

14 Babinski J. Contribution a l'etude des troubles mentaux dans l'hemiphegie organique cerebrale (agosognosie). Rev Neurol (Paris) 1914;27:845-7.

15 Frederiks JAM. Phantom limb and phantom limb pain. In: Frederiks JAM. Handbook of clinical neurology. Vol 1. Clinical neuropsychology. Amsterdam: Elsevier, 1985:395-404.

16 Halligan PW, Marshall JC, Wade DT. Three arms: a case study of supernumerary phantom limb after right hemisphere stroke. F Neurol Neurosurg Psychiatry 1993;56:159sph.

17 Halligan PW, Marshall JC. Supernumerary phantom limb after right hemispheric stroke. F Neurol Neurosurg Psychiatry 1995;59:341-2

18 Critchley M. Disorders of the body-image. In: The parietal lobe. London: Edward Arnold, 1953:225-55.

9 Gilliatt RW, Pratt RTC. Disorders of perception and performance in a case of right-sided cerebral thrombosis. $\mathcal{F}$ Neurol Neurosurg Psychiatry 1952;15:264-71.

20 Mazzoni M, Lucchini C, Meucci G, et al. Supernumerary phantom limb after ischaemic stroke. Neurocase 1997;3: 223-30.

21 Weinstein EA, Kahn RL, Malitz S, et al. Delusional reduplication of parts of the body. Brain 1954;77:45-60.

22 Heilman KM. Anosognosia: possible neuropsychological mechanisms. In: Prigatano GP, Schacter DL, eds. Awareness of deficits after brain injury. New York: Oxford ness of deficits after brain injur
University Press, 1991:53-62.

23 Stuss DT, Benson DF. Theories of frontal lobe function. In: Stuss DT, Benson DF, eds. The frontal lobes. New York: Raven, 1986:230-7. 
24 Steinbach MJ. Eye tracking of self-moved targets: the role of afference. $\mathcal{F}$ Exp Psychol 1969;82:366-76.

25 Fink GR, Marshall JC, Halligan PW, et al. The neural consequences of conflict between intention and the senses. Brain 1999;122:497-512.

26 Gilmore RL, Heilman KM, Schmidt RP, et al. Anosognosia during Wada testing. Neurology 1992;42:925-7.
27 Dywan CA, McGlone J, Fox A. Do intracarotid barbiturate injections offer a way to investigate hemispheric models of anosognosia? 7 Clin Exp Neuropsychol 1995;17:

28 Carpenter K, Berti A, Oxbury S, et al. Awareness of and memory for arm weakness during intracarotid sodium amytal testing. Brain 1995;118:243-51. 